\title{
Experiences with a First International Programme (Philosophy, Politics and Economics - PPE) at Witten/Herdecke University
}

\author{
Batya Blankers ${ }^{1}$, Joachim Zweynert ${ }^{2}$, Jörn Weingärtner ${ }^{3} \&$ Jan P. Ehlers ${ }^{4}$ \\ ${ }^{1}$ Student of BSc Management, Faculty of Management and Economics, Witten/Herdecke University, Germany \\ ${ }^{2}$ Professor for International Politics and Economics, Faculty of Management and Ecomomics, Germany \\ ${ }^{3}$ Chief Internationalization Officer and Managing Director, Faculty of Management and Ecomomics, Germany \\ ${ }^{4}$ Vicepresident and Chair of Didactics and Educational Research in Health Science, Faculty of Health, \\ Witten/Herdecke University, Germany \\ Correspondence: Prof. Dr. Jan P. Ehlers, M.A., Vicepresident, Witten/Herdecke University, Alfred-Herrhausen-Str. \\ 50, 58448 Witten, Germany
}

Received: May 2, 2018

doi:10.5430/ijhe.v7n3p135
Accepted: May 25, 2018

Online Published: May 28, 2018

\begin{abstract}
In 2014, the Faculty of Management and Economics at Witten/Herdecke University introduced its first international programme, the MA PPE, which served as a test case within the overall internationalisation strategy. Despite the challenges detailed in this paper the overall implementation deemed successful. The university derived many valuable lessons for further its internationalisation strategy: embedding an international programme in a clear and structured general internationalisation strategy of the university; offering relevant assistance to international students in all organisational and administrative aspects; actively creating interfaces between international and domestic students; formulating a clear vision and mission for international programmes to be shared equally by students, academic and administrative staff.
\end{abstract}

Keywords: philosophy, politics and economics; faculty development; curriculum development; internationalisation strategy

\section{Introduction}

Internationalisation has become one of the central aims for institutions of higher education, bringing with it new opportunities as well as challenges. Internationalisation is not merely a means to an end, but serves a host of purposes, inter alia preparing graduates for the challenges of a globalised world (including a globalised employment market) and shaping research and/or teaching profiles. It also provides the opportunity to establish cross-border research co-operations, giving students and staff possibilities of intercultural learning and personal development. Finally, internationalisation is a means of quality management and assurance. Equally manifold as the purposes of internationalisation are the forms it can take. Student and staff exchange, teaching in English and language classes as well as courses in intercultural learning are the most common ones. A more ambitious step in this process is the launching of an international programme taught exclusively in English and open to students from highly heterogeneous social, cultural and academic backgrounds. Often, planning such a step in the internationalisation life cycle of a university is hampered by general and/or administrative obstacles leading to the postponement or even the shelving of the implementation. Although some lessons were - and still are being - learned the hard way, this paper and the case described herein are intended to give encouragement to other institutions to take these concerns seriously, but at the same time to encourage institutions to taking bold steps towards further internationalisation.

This paper presents a discussion around the implementation of a new international Master's programme at Witten/Herdecke University (hereafter: UW/H), one of the first private as well as one of the smallest universities in Germany. This programme is taught entirely in English and was created for international as well as home students. The Master's programme in Politics, Economics and Philosophy (hereafter: PPE MA) is the first entirely international programme at UW/H. UW/H has been a pioneer in Germany's tertiary education landscape since it foundation and aims to be at the forefront of innovative change in teaching and research. Alongside new approaches in these fields and the combination of academic rigour with societal relevance, UW/H also actively includes the development of platforms of inter-cultural learning and global exchange through gradual internationalisation. The 
university can sharpen its profile and expand its market share of applications by attracting students from across the globe. Although $\mathrm{UW} / \mathrm{H}$ is a non-for-profit enterprise, this is an important aspect for a private university that competes with a state education system in Germany funded by tax and free of charge for students.

In this context, the university regarded setting up the PPE MA as a test case and forerunner of further internationalisation. The approach, hence, was to learn by doing and to derive experience for possible future internationalisation activities - combined with a justified trust in an organisational setup ready to shoulder the additional burden - the PPE MA was launched. Accordingly, no direct and/or additional steps were taken to prepare the university administrative staff for the challenge of dealing with international PPE MA students, who, very often, could not speak any German at all and were unfamiliar with German academic procedures and structures. Under these considerations and circumstances the PPE MA was launched in 2014.

Precisely because the PPE MA has been established without special preparatory measures, it represents an interesting "natural experiment" of the "what happens if we don't intervene" (Leask and Carroll:2011) type. Our main research questions are simple and straightforward, reflecting our eagerness to obtain lessons for the future: How do international students feel about studying at the university and from their point of view, what needs to change? How does the university administration feel about internationalisation? According to administrative staff and senior management, what needs to change? What can be learned from UW/H's experience to improve the programme? The empirical paper is methodologically based on grounded theory, thus on qualitative interviews with staff members (both academic and administrative), international and national students. In the next section, a brief introduction is given on the history and vision of the programme. Section three introduces our methods and interview questions. In section four, we present our results which we then discuss in the fifth and main part of the paper. Section six concludes.

\section{History and Vision}

UW/H was founded in 1983, the Faculty of Management and Economics of UW/H was established in 1984. Based on the university's ideal of pluralistic theoretical approaches, broad education (in contrast to vocational/professional training which is very specific and limited), personality development, and practical relevance, it offered a programme combining management studies with economics. The programme was characterised by strong interaction with so called "mentor companies"' in which students could gain practical experience. Additionally, it systematically aimed at going beyond pure business administration. One of the unique aspects of $\mathrm{UW} / \mathrm{H}$ is the mandatory "studium fundamentale" (interdisciplinary fundamental studies) offered by the Faculty of Humanities and Arts making up 10 per cent of study content and, within the core course, by the establishment of a chair in economic philosophy with the task to provide an - in the traditional sense of the term - 'humanist counterweight' to the studies of management and economics.

During the Bologna reform in 2009, the Faculty of Economics and Management and the Faculty of Humanities and Arts jointly decided to go one step further towards the integration of economics and humanities and to establish a PPE programme at Bachelor's level, predominantly taught in German. Once the programme had gone through its teething problems (amongst other things, the main initiator leaving the university shortly before the launch of the programme), the PPE BA proved to be a great success in terms of its value as an academic qualification and observed in the increase of the quantity of applicants. Students and staff felt that PPE was perfectly in line with UW/H's idea of integrative and socially engaged science.

Given this positive experience, it was an obvious next step to establish a corresponding programme at Master's level. As with the BA programme, the initiative hailed from the Faculty of Management and Economics. The initiators agreed from the outset that at MA level a PPE programme had to be international and thus to be taught entirely in English. The main reason for this is that, when asked about their career aspirations, the clear majority of PPE students expressed their wish to work in international organisations, NGO's or business contexts. Hence, for the design of the programme, it was imperative not only to offer instruction in English but also to create an international classroom where an international student community could foster their intercultural skills. This implied on the part of the institution the creation of a surrounding to promote the development of soft skills even within the perimeter of the course. Further reasons for the faculty's preference for English as language of instruction were to make the programme more attractive for current BA students who, in view of the initiators, would not be won over by a "more of the same" approach for subsequent graduate studies at UW/H; and the faculty's aim to deepen the basis for international co-operation which proved increasingly difficult to establish due to the restricted number of classes in English offered at BA level. 
First meetings with representatives of the Faculty of Humanities and Arts in autumn 2012 quickly revealed that there was no shared vision for an international programme exclusively taught in English. The Faculty of Humanities and Arts largely supported the proposal of a programme that was partly or even predominantly taught in English. However, for academic (e.g. Why should one teach German idealism in any other language than German?) as well as administrative reasons (stretching the capacities of administrative and academic staff through additional workload), the Faculty of Humanities and Arts did not join the MA programme. Based on this, the Faculty of Management and Economics decided to establish the programme independently from the Faculty of Humanities and Arts.

The accreditation process was completed in spring 2013 and the first intake of students was scheduled for winter semester 2013/14. It soon became clear, though, that the university had underestimated the challenge of launching such a programme on the international market effectively in terms of marketing and public relations as all previous activities in this department had been designed solely for the German market. The programme directors, the newly installed managing director of the faculty and members of the marketing department formed a task force and developed an international marketing campaign on an ad hoc basis. Because of these difficulties, the programme start was postponed to autumn 2014/15 with a first intake of seventeen students (one student dropped out after commencing the course due to academic and financial strains reducing the first cohort to 16). However, despite increasing support and expertise from the marketing department and a very high student satisfaction in the first cohorts, attracting students from across the globe remains one of the major challenges. The paper refrains from going into more detail about this aspect as it is not part of the core discussion.

A fundamental aspect of UW/H's PPE programme is its conscious disregard for the boundaries between academic disciplines in terms of observing and questioning problems and challenges of the $21^{\text {st }}$ century. In contrast, academia is currently more fragmented and compartmentalised than ever before. As a result, experts usually only comprehend certain aspects of the complex problems that are typical for a globalised world. What is missing are generalists with a broader vision combining the insights of more than one academic discipline. At the same time, the multi-disciplinarity creates the main challenge of PPE programmes from a didactical perspective. There are different strategies to address this challenge. A common solution is that philosophers, political scientists and economists agree on a certain range of theories and methods before engaging themselves and their students in interdisciplinary discourse. Typically, these types of programmes have a strong theoretical direction often with a focus on decision-making. They are based on a methodological canon that focuses on public/rational choice, game theory and analytical philosophy. This solution of tackling the problem of inter-disciplinarity by developing a narrow canon of theories permitted for a PPE programmewould run counter to the philosophy of UW/H. PPE at UW/H takes $21^{\text {st }}$ century problems (Poverty and Globalisation, Climate Change, the Global Commons) as a starting point and asks what the different academic disciplines, with their essentially different perspectives, can contribute to understanding and solving these problems. This is the basis from which different perspectives are explored and then combined, thus students create a holistic picture of the real world $21^{\text {st }}$ century problems. Therefore, UW/H refers to the programme as a "Real World PPE" which is didactically near to experience based learning (1).

In line with the didactical concept of UW/H (3), the design of the programme leaves ample space for students to bring in their preferences and to engage in their own research. For example, in each semester there are several classes titled "Current issues of..." and "Questions at the interface of ..." the content of which is agreed upon beforehand with the students. (Note 1) The main instruments that enable students to conduct their own research are so-called independent studies and projects. Students who come across a problem they would like to explore are invited to find a supervisor, with whom they define the exact topic, develop their hypothesis and determine how they want to present their results (usually an essay of 20 to 25 pages). Furthermore, student researchers are encouraged to discuss their findings with a wider audience. One of the forums at which the results of independent studies and projects can be presented is the annual Witten International PPE Student Conference. The International PPE Conference has been taking place since 2016. It is organised by Witten PPE students (both from the BA and the MA level) and offers an international forum for students' research in the field of PPE and related multi-disciplinary programmes. The first two conferences were attended by approximately 80 students from all over the world.

\section{Methods}

To learn more about the outcomes of the "spontaneous internationalisation" that had been set off by introducing the PPE MA and to answer the study questions, we conducted semi-structured interviews with the main stakeholder groups, which are

- international students

- German students 
- administrative staff members and

- lecturers teaching in the programme.

Interviews were carried out with randomly selected candidates from each stakeholder group to ensure that we could establish a holistic picture when observing the vision in practice. Our guideline for structured interviews contained the following questions:

Main Question = numbered

Supporting Question = bulleted

1. What has your experience been of the international PPE Master programme at Witten/Herdecke University?

o When did you first hear about it?

o In what way has the programme affected your working life/life?

Ask further questions based on answer to above to get more details

2. What has changed for $\mathrm{UW} / \mathrm{H}$ with internationalisation?

o What has worked and what has not worked?

o Provide examples

o Tell me stories

3. What are your hopes for the future?

o Is there anything that you would change?

o What would you not change?

4. Is there something else you would like to add or share with me?

The interviews were audio recorded and had a length between 15 and 35 minutes. Afterwards, they were transcribed and imported into MaxQDA for a qualitative content analysis following the methodology proposed by Mayring (2011) and "Grounded Theory" (12). The transcripts were openly coded and categorised. Codes and categories as also the quotes were discussed in the research group to prevent a status-quo bias and to create new theories about the influencing factors of internationalisation in a small university. In total, 12 individuals were interviewed.

\section{Results}

The interviews revealed that there are three main problem fields around the PPE MA: Study contents and vision of the programme, interaction between international students and administration, and intercultural competences/integration of international students within a previously national university. Our presentation of results follows these three focal points.

\subsection{Observing a Vision in Practice}

Our interviews with students revealed a very high student satisfaction. The international character of the programme was repeatedly mentioned as a particularly positive feature and the experience of intercultural learning was in some cases reported to have changed the way students see the world. Subject One (hereafter S1) describes the atmosphere and interaction in class as a space where students "have other perspectives and people get very engaged" (S1). She/he continues that "the programme is very international. Half of [the] students are international." Furthermore, various participants reflected on the development of their own knowledge and thinking over the last couple of semesters, they expressed how their international perspective broadened over time. S3 says "[the programme] has really given me an international perspective and content-wise I have become very aware of the world." The didactical methods were described as very positive: "In Witten, teachers are more willing to discuss ideas" and encourage students constantly to "challenge mainstream ideas." (S1). However, whereas students are overall highly satisfied with the course and its contents as such, some students criticised that they did not know what the broader vision for the programme is or what the concrete occupational profile of a graduates is. It is not clear where the programme is directly heading and, closely connected, who the actual target group is and why UW/H introduced such a programme.

The administrative staff - all on the clerical, not the management side -, on the other hand, share a view on the vision and setup of the programme. One rationale about the programme that was shared was "to have as many international students here as possible" (S4). Some did not know the overall vision of the programme or what the 
institution would like to achieve by having an international PPE Master at a German University. "I was only included in developing this programme at a later stage, and even when I became involved the vision was not clear to me."(S5)

\subsection{Administration}

From an administrative point of view, fundamental changes or innovative steps necessitate certain pre-requirements and - at the same time - raise a set of expectations. All administrative staff interviewed emphasised that they had hitherto worked in a purely German speaking context. These participants also stated on several occasions that they welcomed and enjoyed the new challenge that comes with having to speak English more regularly at the workplace. However, they also mentioned as well that they were aware of colleagues who did not approve of this change and new departure. Although "[s]ome older colleagues can speak English (...) they don't trust themselves to do so." (S5)

On the more operational side, some administrative staff stated that their workload had increased. "The telephone calls [with international applicants] also do cost time. And then there are many applications that need to be processed and time is tight." (S4). Another related the workload to the manpower of the (small) university: "I think it is a structural problem at the university because we have many part time positions. And it works as long as everyone is here. But as soon as someone is sick or on holiday, it becomes difficult because then other people need to cover for this person." (S5) Administrative staff generally suggested installing one contact person to manage all PPE Master student queries, from applications, to assisting students with their preparation for the move to Germany and being available for current student's queries.

Interviewees also spoke about adapting the current application process to the needs of international applicants. "We need to treat the applicants more carefully. They should apply by March or April so that they even stand a chance to make it to Germany by October." (S5) This refers mainly to visa procedures (indeed there were students who commenced their studies with a significant delay), but also to the bureaucracy at German institutions where non-German applications are not familiar with requirements. "Applicants experience [a] culture shock in terms of bureaucracy, for example the exmatriculation forms they need to provide." (S5). (Note 2) Another reason to adjust the application procedure is that the admissions office "really need[s] time to vet the certificates and degrees. For many, a two-semester master programme is more interesting and there we need to check if they have the correct amount of credit points to be able to do this." (S4).

Some interviewees from the administrative staff feel that the overarching organisational structures do not sufficiently support the process of internationalisation: "(...) one does not get a general feeling for internationalisation or the fact that there are foreigners attending the university. I have the feeling that it is forgotten in the daily rhythm." The positive effects of the internationalisation were described differently "I find the internationalisation at our university a positive aspect, it also enriches my work" [but] "I don't think everyone may see it as positive because people are different." (S4)

Students had mixed responses when speaking about institutional support: "Maybe it is because the unit is so small or because of the location, but not all the staff have realised that it is becoming more international"; "I think it would be good if there was more awareness around internationalisation. For instance, info emails [sic] that are sent out should be done in English and German, often this is forgotten. Not on purpose, but just because it is not in one['s] consciousness." (S2), "What would be great is if we had an overall university strategy, like employee training in terms of internationalisation."(S3)

Also, the students suggest installing one coordinating person for the international curriculum: "I don't understand why there isn't one administrative person to support the international students. I don't think the university realises what it means to set up a life here in Germany."(S10) (Note 3) However, some student respondents pointed out that the programme has already become more international ("Somehow it feels like it is international now.") and expressed the hope that with a further increasing number of foreign students' integration will become easier.

\subsection{Intercultural Competencies/Integration}

Apart from the administrative obstacles, international students in the PPE MA also faced unexpected academic challenges. The amount of work and the way it is evaluated seems to be very different for a lot of the students from what they were used to from their home/undergraduate institutions. Many of them stated that the workload is high and takes some time getting used to: "Even my German colleagues are having problems with keeping up" (S1); "We did not receive any type of orientation or workshop in what is expected of us and how we will be marked." (S9). Problems have been clearly identified and changes have been suggested and made "[The new] first and second semester spent a lot of time understanding the German system." (S7) 
Finally, the role of professors was seen and conceived in various ways depending on the individual background. Some experienced professors as "very accessible." (S3) Others, and this statement can in our view clearly be regarded as a reflection of intercultural differences, stated that despite the attested general accessibility " $a$ professor has a title. Could not ask for help from them because of hierarchy, and would only approach them with academic questions." (S2)

\section{Discussion and Implications}

The results shown in the previous section allow the central conclusion that so far, the PPE MA programme could be seen as an island or a 'state within the state' of the university. Once the students have arrived on this island, they are highly satisfied with the contents of the study programme, with the instructors and with the international and intercultural student community in their programme and beyond. It would be an exaggeration to say that the PPE-island is isolated from the rest of the university, especially after a run-in phase of three years. But it is also obvious that there is the widely shared perception that better integration into the organisation is needed. Firstly, to give international students the full benefit of studying in Germany within the context of an international study programme, secondly, to learn from the experience of this trailblazing experiment.

In particular, international students perceived a lack of support from the university administration in terms of integration - academically and socially. Conversely, international students tend to prefer to help each other and to seek each other's' support rather than approaching the university directly. Various answers both by students and by administrative staff suggest that so far there is no shared understanding whether Witten/Herdecke is or wants to become an international university.

In the case of UW/H, this comes as no surprise as the PPE MA is seen as a pioneering project within the internationalisation strategy at UW/H. Until recently, internationalisation was regarded as an "icing on the cake" rather than a stock ingredient of the institutional development (Note 4). It is not surprising that this experiment was started within the Faculty of Management and Economics which has the greatest drive, but also the greatest need for internationalisation in order to remain competitive. In the Faculty of Health and the Faculty of Humanities and Arts, internationalisation is not necessarily regarded as a profile-building measure. The experiment of the PPE MA has produced some important lessons, sometimes learned the hard way. The key learning is that a solitary experiment will soon meet its limits. Building on the experience of the Master PPE, the university is now in a structured process of internationalisation based on a clear, written and publicised internationalisation strategy. An interdepartmental steering committee under the leadership of a newly appointed Chief Internationalisation Officer is now working to monitor the progress of implementation of the comprehensive internationalisation strategy in the three key areas of teaching, research, and administration. Furthermore, UW/H is in the process of establishing a second international programme in the field of digital transformation. Finally, the Faculty of Management and Economics has also established several double degree programmes with international universities on both graduate and undergraduate level. Generally, the experience of the PPE MA shows that introducing an international programme should ideally be accompanied by more systematic measures of change management that aim at creating a shared vision of the university as a whole. As a simple example on low, but easily underestimated level, the daily menu of the cafeteria is now displayed additionally in English. On the more cultural level of a university, it seems necessary that the university has a clear vision of

a) the aims of the programme for the positioning of the university,

b) the educational aims of the programme and,

c) thus, of the professional prospects of its graduates on the employment market (4).

Furthermore, these visions and ideas need to be fully understood and shared on the academic level both by faculty members and students and - probably to a lesser extent - by the administrative staff. Finally, these visions and ideas have to be publishable and published.

Changing the perspective from the purely academic to the more organisational matters and needs of students, it seems necessary to provide help and assistance to international students in settling in in their new academic and social environment. To stay in the Witten picture: Before international students arrive at Witten's PPE island, they have to overcome the gap between their domestic educational backgrounds and the German educational system. Our interviewees felt that German academic standards are higher both in terms of workload and intellectual demand. This asked for a prolonged introductory/welcome session - including an intensive German course - in which the university helps international students to soften the cultural shock: As much as students seem to enjoy Witten didactics once 
they have gotten used to it, interactive small-group instruction for many if not most international students can be an acquired taste. The same applies to German administration, university-related and generally.

In this context, both students and administrative staff made one suggestion independently of each other, i.e. to create the position of a specialised contact person which PPE MA students could contact in regard of all kinds of administrative issues. From our experience, we see opportunities and risks here. Whilst it might facilitate services to international students due to specialisation, it might at the same time deepen the trenches between international programmes and students and thus keep the worlds apart. This would be counterproductive, although international programmes inherently must have the aim to invite the world to the respective university and make it at home, international students should not be kept in an international bubble, but exposed to the culture, academic as otherwise, of their new (temporary) homes (7). Furthermore, institutional learning would be hampered by keeping both worlds apart and perpetuating the gap between parts of the administration and the PPE MA. However, if this position would be explicitly meant to work as an intersection between students and administration (so that the person in charge would mainly act as a consultant that helps students to identify the correct contact person and to support them in case that they encounter difficulties) this certainly could be an institutional solution that might contribute to building bridges between international students and administration.

\section{References}

Andresen, L./Boud, D./Cohen, R. (2000). Experienced Based Learning. In: Foley, G. (Ed.): Understanding Adult Education and Training. $2^{\text {nd }}$ Ed., Allen \& Unwin, 225-239.

Bartell, M. (2003). Internationalization of universities: A university culture-based framework. Higher education, 45(1), 43-70. https://doi.org/10.1023/A:1021225514599

Butzlaff, M./Hofmann, M. (2014). E 8.20 Der Modellstudiengang Medizin an der Universität Witten/Herdecke - auf dem Weg zur lebenslang lernfähigen Arztpersönlichkeit. In: Handbuch Qualität in Studium und Lehre.

Engelke, J./Müller, U./Röwert, R. (2017). Erfolgsgeheimnisse privater Hochschulen. Wie Hochschulen atypische Studierende gewinnen und neue Zielgruppen erschließen können. CHE.

Hiller, G.G./Vogler-Lipp, S. (2010). Schlüsselqualifikation Interkulturelle Kompetenz an Hochschulen: Grundlagen, Konzepte, Methoden. Springer-Verlag.

HRK-German Rector's Conference. (2015). Building upon International Success. https://www.hrk.de/audit/fileadmin/redaktion/hrk-audit/Infothek/HRK-Audit_Building_upon_International_Suc cess_01.pdf

Isserstedt, W./Schnitzer, K. (2002). Internationalisierung des Studiums: ausländische Studierende in Deutschland; deutsche Studierende im Ausland. Bundesministerium für Bildung, Wissenschaft, Forschung und Technologie

Jones, E./Coelen, R./Beelen, J./de Wit, H. (2016): Global and Local Internationalization, Sense

Leask, B./Caroll, J. (2011). Moving beyond 'wishing and hoping': internationalisation and student experiences of inclusion and engagement. Journal Higher Education Research \& Development 30(5), 647-659. https://doi.org/10.1080/07294360.2011.598454

Mayring, P. (2010). Qualitative Inhaltsanalyse. Handbuch qualitative Forschung in der Psychologie. VS Verlag für Sozialwissenschaften. 601-613. https://doi.org/10.1007/978-3-531-92052-8_42

Schmeken, C. (2011). Wo bitte geht's hier nach Bologna? Ohne Blick nach draußen kommt die Reform nicht ans Ziel. Zeitschrift für Hochschulentwicklung ZFHE Jg. 6(2). https://doi.org/10.3217/zfhe-6-02/23

Strauss, A./Corbin, J.M. (1997). Grounded theory in practice. Sage.

Teichler, U. (2007). Die Internationalisierung der Hochschulen: Neue Herausforderungen und Strategien. Campus Verlag. 


\section{Notes}

Note 1. To give an example: A student approached the program directors with the request to organize a current issues course on post-growth economics and suggested a Canadian expert he had met at a conference. As the proposal was supported by a sufficient number of students, the expert was invited to teach the course and, as the seminar proved highly successful, now regularly teaches at $\mathrm{UW} / \mathrm{H}$.

Note 2. Not all universities across the world provide students with a de-registration certificate (exmatriculation). Their degree certificate is regarded as equivalent.

Note 3. Whereas there is no administrative staff particularly assigned to the MA PPE programme, UW/H has an international office that offers services to graduating as well as non-graduating students. Furthermore, within the Faculty of Management and Economics, there is a course co-ordinator and a student initiative dedicated to international students and internationalisation.

Note 4. To a high degree, this is also owed to the profile of the university. The by far largest faculty is the Faculty of Health including Schools of Medicine, Dentistry and Psychology which are highly international in terms of research, but less open for internationalisation in terms of teaching as German is incontrovertibly the language of tuition and practical experience. 